\title{
Nominations to the Fellowship of The Royal College of Psychiatrists
}

At its meeting on 15 February 1993, the Court of Electors approved the following guidelines for sponsors nominating Members of the College to the Fellowship.

\section{Sponsors}

(i) Each nomination must be supported by two sponsors, both of whom must be subscribing Fellows of the College.

(ii) Sponsors must not be members of the Court of Electors at the time of submitting their nomination.

\section{Eligibility of candidates for the Fellowship}

(i) The Fellowship is ordinarily awarded to a Member for distinction in teaching, research, clinical and/or administrative ability, or for exceptional service to patients, especially where supportive staffing is inadequate. Sponsors should indicate any factors which go beyond the carrying out of consultant or academic duties by the candidate of their choice.

(ii) The Court of Electors will also take into account the contribution the candidate may have made to the activities of the College.

(iii) It is unlikely that the Court will consider an individual with less than ten years seniority as a Member to be eligible for election to the Fellowship. There are other circumstances, also, in which the Court may consider election to be inappropriate - for example, in the case of a consultant who has lost approval as an educational supervisor.

(iv) Candidates for the Fellowship should be subscribing Members of the College at the time when nominations are submitted. Sponsors will be notified if this is not the case.

(v) If the candidate is practising overseas, one of his/her sponsors should be a Fellow working in the same country. The Court may waive this requirement should there be no Fellows in a particular country.

\section{Nomination forms}

(i) Sponsors are reminded that it is their responsibility to complete the citation and curriculum vitae forms on behalf of their nominee. Nominations may be returned if these forms have not been completed by the sponsors.

(ii) Both the citation and the curriculum vitae must be confined to the forms provided, and no other documentation will be considered. The curriculum vitae should include the candidate's date of birth, date of obtaining the Membership of the College and date of achieving consultant status. No more than ten recent and pertinent publications should be cited.

(iii) The forms must not be written by hand, but should be typed or word-processed.

\section{Results of elections}

(i) All successful candidates and their principal sponsors are notified by the College. Elected Fellows become entitled to use the designation "FRCPsych" after they have paid the prescribed registration fee.

(ii) Principal sponsors of unsuccessful candidates are also notified, and are asked to inform their nominees accordingly.

Court of Electors 